\title{
Understanding Life under Public Scrutiny: The U.S. Bio-pharmaceutical Industry Experience
}

\author{
Ying Jenny Zhang \\ Correspondence: Ying Jenny Zhang, Department of Finance and General Business, College of Business \\ Administration, Missouri State University, Springfield, MO 65897, USA. Tel: 1-417-836-5348. E-mail: \\ YJennyZhang@MissouriState.edu
}

Received: June 3, 2012

Accepted: June 29, 2012 Online Published: August 8, 2012

doi:10.5539/ibr.v5n9p195

URL: http://dx.doi.org/10.5539/ibr.v5n9p195

\begin{abstract}
The pharmaceutical and biotechnology industry is a major component of the global health economy, of which, the U.S. plays an important role and attracts firms from all over the world to operate and sell products in it. This paper provides an overview of the regulatory environment in the U.S. and reviews relevant finance literature on this industry. Two particular pieces of legislation, the FDA fast track designation and the Orphan Drug Act, both of which have been shown to have significant impact on the financing and product development of firms, are also described in this paper. In addition, this paper surveys the recent U.S. financial market volatility and its effect on firm’s financing opportunity.
\end{abstract}

Keywords: bio-pharmaceutical industry, product development, public firm, equity financing, fast track designation, Orphan Drug Act

\section{Introduction}

According to data published by the Organisation for Economic Co-operation and Development (OECD), the health care spending has been rising over the past 40 years in major developed countries. As of 2008, it ranged from $\sim 8 \%$ of GDP in Japan to $~ 16 \%$ in the U.S., and the spending keeps on going up. (Note 1) The pharmaceutical and biotechnology industry is one of the major industries in the healthcare sector (Gapenski, 2012). (Note 2) Unlike other industries in healthcare, e.g. health services or insurance industry, most of which are operated and financed domestically, firms in the pharmaceutical and biotechnology industry tend to expand internationally given the universal applicability of their products. Major players in this industry, such as Pfizer, GlaxoSmithKline, Roche, Bayer, etc. are all multi-national corporations with worldwide operations. The U.S. plays an important role in the global health economy and attracts firms from all over the world. This paper provides an overview of the regulatory environment of the pharmaceutical and biotechnology industry in the U.S., and reviews recent research on firm's financing and growth strategies.

Given the fact that, in recent years, most pharmaceutical firms utilize biotechnology in drug discovery, testing, and manufacturing either through acquisition or in-house development; while used-to-be pure-play biotech firms often resort to the "corporate venture" arms of big pharmaceuticals for financing and strategic alliance in attempts to advance their development and to commercialize their technology or therapeutic agents, the distinction between traditional pharmaceutical and biotechnology firms is quite blurred nowadays. Hereafter in this paper, the word bio-pharmaceutical is used to refer to the entire "pharmaceutical and biotechnology" industry.

On the operational side, bio-pharmaceutical firms operating or selling (or attempting to sell) products in the U.S. must comply with regulations set by the U.S. Food and Drug Administration (FDA), arguably the most stringent standards worldwide. The research and development $(R \& D)$ of a new pharmaceutical or clinical product is a lengthy and costly endeavor. Recent study shows that on average, it takes eight to ten years and costsoverone billion dollars to bring a new drug to the market. (Note 3) In the meantime, the failure rate is extremely high-only one in thousands of chemical compounds eventually passes the whole process from the laboratory to clinical trials and finally makes it to the market as a new drug.

To finance such lengthy, costly, and highly risky operations, bio-pharmaceutical firms often turn to the capital market for public equity financing via selling stocks to the investment community. Well-known pharmaceutical giants—such as Pfizer, Merck, and GlaxoSmithKline_-as well as highly successful early biotech players—such as Amgen, Genentech, (Note 4) and Gilead Sciences-plus many more lesser-known firms, are all public firms with 
shares traded on U.S. capital markets on a daily basis. Firms with publicly-traded securities in the U.S. must abide by rules and regulations set forth by the U.S. Securities and Exchange Commission (SEC).

This paper reviews how regulations by the two agencies, the FDA and the SEC, interact and pose a unique environment for bio-pharmaceutical firms in the U.S. Given the limitation of space and the author's own research interest, emphasis of this paper is placed on the interaction of FDA and SEC rules that facilitate insights about the corporate structure, operational success, and financing options of firms. Two pieces of legislation, the FDA fast track program and the Orphan Drug Act, which have drawn a high percentage of application from small bio-pharmaceutical firms, are also reviewed. Mini-cases on real companies are included to provide live examples of the issues.

The rest of this paper is organized as follows: Section 2 reviews the Initial Public Offering (IPO) literature and the IPO activity in the bio-pharmaceutical industry in recent years; Section 3 describes the regulatory environment for bio-pharmaceutical firms and reviews research on firm performance and growth strategy; Section 4 discusses the follow-up financing and growth options of firms; Section 5 describes the FDA fast track program and the Orphan Drug Act; Section 6 surveys recent market volatility and concludes the paper.

\section{Going Public}

There are, generally speaking, two ways to finance a business: equity financing and debt financing. Both can be done either publicly, meaning open to all investors, or privately, with only a select group of investors being involved. Most firms start with private funding. After they survive the start-up stage and prove themselves to be viable or profitable, they turn to public equity financing via the Initial Public Offering (IPO) process.

The major benefits of going public versus remaining private are twofold: First, it allows the founding entrepreneurs as well as the venture capitalists to "cash in" their success by exchanging private ownership to publicly tradable shares; second, once publicly traded, the firm has better access to the capital market to finance future growth. It has been documented that IPOs come in cycles, and high IPO volume tends to follow high market valuation (Ritter, 1998). For biotech firms in particular, Lerner (1994) shows that IPO waves coincide with high market valuation of this sector, and, when market condition is less favorable, biotech firms stay private with venture capital funding. Anderson and Zhang (2011) show that IPO activity in the U.S. during 1996-2004 in the bio-pharmaceutical industry corroborates existing literature on IPO cycles. During the year 2000, the peak of the so-called "technology bubble" period, 25 bio-pharmaceutical firms went public, raising \$1.352 billion in total proceeds. After the tech bubble burst, however, only three IPOs in 2001, and another three in 2002, raising \$247 million and \$445 million, respectively. IPOs returned in high volume in 2004 after market condition improved with 26 new issues, raising $\$ 1.5$ billion.

As with any benefits, there are costs. Public firms in the U.S. must comply with the regulations under the Securities and Exchange Commission (SEC), such as frequent reporting of operating performance and executive compensation, and timely and fair disclosure of material information about the condition of the firm, among many other things. Firms also have obligations to their outside investors and must maintain good relations with them. Keeping up with regulatory compliance and maintaining good relation with investors all take time and money for public firms, which should be taken into consideration for firms contemplating going public.

For bio-pharmaceutical firms that engage in the discovery and development of products in the U.S. for human and animal use, the Food and Drug Administration (FDA) is another regulatory body whose requirements firms must satisfy. The next section reviews FDA and SEC regulations that apply specifically to bio-pharmaceutical firms.

\section{The Regulatory Environment for Public Bio-pharmaceutical Firms in the U.S.}

\subsection{The FDA Aspect}

The research and development of a drug in the U.S. consists of two stages: pre-clinical testing and clinical testing. In the pre-clinical stage, a chemical or biological compound is investigated in the laboratory with regard to its potential for therapeutic application, which may involve testing on animals (rats, dogs, or monkeys). When pre-clinical test results prove the compound to be a viable drug candidate, the firm must file an Investigational New Drug (IND) application with the Food and Drug Administration (FDA) in order to proceed to test human subjects. Only after the IND is approved by the FDA can the sponsor firm initiate the clinical testing of a drug candidate on humans. Drugs derived from living organisms are referred to as biologics. They follow the same clinical testing regimen as traditional drugs that are based on chemical compounds.

The clinical testing consists of four phases: Phase 1 tests the drug candidate on healthy humans for safety evaluation; Phase 2 tests the efficacy of the drug candidate on 20 to 50 patients with the target illness; Phase 3 also tests the drug's efficacy, but on a much larger scale, and sometimes involves thousands of patients at various 
locations; Phase 4 consists of ongoing post-market monitoring of drug safety and efficacy. All phases of clinical testing must conform to FDA guidelines and must be reported to and approved by the FDA. Upon completion of Phase 3 clinical trials, if there is sufficient evidence of satisfactory safety and efficacy results, the sponsor firm must file a New Drug Application (NDA) with the FDA for marketing approval of the drug. Only after the FDA approves the NDA can the drug be launched onto the market. The entire drug approval process, from its discovery to the market, takes an average of 8-10 years and costs approximately one billion dollars on average. (Note 5)

Even after a drug is on the market, the drug manufacturer is responsible for monitoring the effects of the drug and communicating with the FDA and patients on any adverse effects of the drug not revealed by earlier clinical testing. This is normally referred to as Phase 4 continuous testing. High-profile cases in recent years of safety and efficacy issues discovered during the market phase include Vioxx and Avastin. Vioxx was approved by the FDA in 1999 and was marketed by the pharmaceutical giant Merck as a pain killer. By 2003, worldwide sales of Vioxx reached $\$ 2.5$ billion. Post-market monitoring, however, revealed "an increased risk of serious cardiovascular events, including heart attacks and strokes, in patients taking Vioxx compared to patients taking naproxen” which triggered a voluntarily withdrawal of Vioxx from the market by Merck. (Note 6) In the Avastin case, the FDA revoked its approval of this breast cancer drug in 2011.As the FDA commissioner said in the news release, "After reviewing the available studies it is clear that women who take Avastin for metastatic breast cancer risk potentially life-threatening side effects without proof that the use of Avastin will provide a benefit, in terms of delay in tumor growth, that would justify those risks. Nor is there evidence that use of Avastin will either help them live longer or improve their quality of life.” (Note 7) Such market withdrawals (either voluntary or involuntary), although rare, demonstrate that the FDA closely monitors the safety and efficacy of drugs at all stages, even after they are on the market.

As described above, the research and development of a drug is lengthy, costly, and risky. It is estimated (Lipsky \& Sharp, 2001) that out of 5,000 chemical compounds tested in the pre-clinical stage, roughly 5 (0.1\%) advance to the clinical testing stage, and only 1 of the 5,000 eventually makes to the market as a drug. The pass-through rates at each clinical phase are roughly $20 \%$ for Phase $1,40 \%$ for Phase 2, and $60 \%$ for Phase 3 . Approximately $70 \%$ of all NDAs are approved.

Since the drop-off rate during the pre-clinical stage is very high, firms rarely disclose their pre-clinical portfolio. The results of clinical testing, especially of Phases 2 and 3, reveal drug candidate potential, therefore are of particular importance to investors for valuation purposes. Public disclosure of clinical trial development is not mandated by the FDA; neither does the FDA maintain a database on such information. For public firms in the U.S., the SEC does require disclosure of material information to investors in a timely manner. Although the SEC does not specify clinical testing results as material information, they definitely qualify, especially to small firms which normally have only a few drug candidates in their research and development portfolios and none on the market.

Given the nature of the drug development process, the valuation and even the viability of small-or medium-sized bio-pharmaceutical firms closely hinges upon the outcome of each clinical testing phase. A positive clinical result means more possible funding - a better chance of developing strategic alliances with established pharmaceutical firms that have abundant resources and experience in the subsequent drug approval process. A negative clinical trial result, however, may mean the end of life for a drug candidate or even for the entire firm if there is no other promising compound in the firm's portfolio or if there are not enough resources to invest more in the current compound. The next section discusses the SEC regulation and how it interacts with that of the FDA.

\subsection{The SEC Disclosure Requirement}

The SEC requires all public firms in the U.S. to disclose their operational and financial conditions on a quarterly basis in their 10-Q filings. The financial statements in the 10-Q, however, are usually not "audited", meaning that they are without the scrutiny of certified public accounts (CPAs). Every fiscal year, firms also must file an annual report to give detailed information on their operational performance, financial condition, management analysis of the market condition, etc. Such an annual report is called a 10-K, and the financial reports included herein must be audited and endorsed by the top management of the firm. Besides the quarterly (10-Q) and the annual (10-K) reports, the proxy statement (schedule 14A) is used to report issues that need shareholder approval. The proxy statement also contains detailed information on top managerial personnel and their compensation. Another often used filing form is the 8-K, through which firms report "current company information" to investors.

Aimed at promoting "full and fair disclosure" of material information, the SEC adopted the Regulation Fair Disclosure (Reg. FD) in August 2000, under which, news releases must be made to the public rather than to a selected few. (Note 8) Most firms do follow SEC guidelines, yet some try to "time the news release" for their 
advantage. One such case is included in the appendix where six-year-old "news" was released in attempt to mislead investors.

Not only information of the public firms themselves, but also the trading of these stocks by mutual funds and by the firms' own top managers are required to be reported to the SEC. Forms 3, 4, and 5 track insider ownership and transactions; form $13 \mathrm{f}$ reports mutual fund holdings. The SEC maintains a searchable online database called EDGAR where all filings since 1984 by public firms can be retrieved. For a detailed description of every filing form and how to use the EDGAR database, please go to http://www.sec.gov/investor/pubs/edgarguide.htm.

The next section discusses how these regulations facilitate research of bio-pharmaceutical firms.

\section{Corporate Structure, Firm Performance, and Financing Options}

The sequential clinical trials required by the FDA prior to granting approval to market products provide a unique opportunity for research on corporate structure, firm performance, and financing options. This staged development regimen allows firms to re-evaluate their growth options as they complete each phase of testing and to restructure the organization if appropriate or necessary. It also provides information to investors about the expected future performance of a firm as clinical trial results are released to the public. Better financing choices and cheaper costs follow naturally good operational performance, and vice versa.

There are a few very successful stories in the bio-pharmaceutical arena, such as Genentech, Amgen, and Gilead, which have advanced medicines in the treatment of life-debilitating diseases and have become the industry leaders. Nevertheless, the majority of the young public firms in this sector remain in the developmental stage without having any drug approved for marketing years after their IPOs. Guedj and Scharfstein (2005) compare the drug development success rates of young single-product firms to those (relatively) mature firms with multiple drug candidates. Their results suggest that young firms tend to overinvest in the R\&D of speculative drugs in an attempt to "swing for the fences" and achieve an unlikely breakthrough. The authors further conjecture that the internal capital market (through which mature firms allocate funding for multiple drug candidates) is more efficient than the external capital market (where young firms with a single drug candidate get funding).

The separation of ownership and control in public companies, where agents/managers, not the investors/owners, make operational decisions for the firm, give rise to the agency problem. Managers, having their career and reputation at stake, tend to be driven by wishful thinking and to be overly optimistic about drug candidate potential, thus they keep investing shareholder money despite early signs of failure. Such practice can last for years and can destroy shareholder value given the time consuming and complex nature of the drug development process. Therefore, more transparent disclosure, closer oversight by investors, and better corporate governance are needed to best utilize resources and enhance returns to investment.

Money raised in IPO can usually keep a bio-pharmaceutical firm running for one to three years, after which the firm has to raise new financing if it cannot generate enough cash flow internally to sustain its operation. It is unlikely that a newly public bio-pharmaceutical firm can achieve self-sufficiency before the IPO money runs out. Due to lack of operating profitability, the use of debt for financing in this sector is rare. Lerner, Shane, and Tsai (2003) show that small biotech firms form "strategic alliances” with large pharmaceutical firms to jointly develop drug candidates in "cold" market when equity valuations are low and equity financing is difficult to obtain. When the stock market improves, however, such co-development contracts are re-negotiated in favor of small biotech firms, given better market condition and easier access for equity financing. In addition to monetary infusion, small biotech firms also benefit from alliances with big pharmaceutical firms in terms of regulatory expertise to advance drug candidates through the approval process.

Since the mid 1990s, private investment in public equity (PIPE) has grown significantly and recently surpassed seasoned equity offering (SEO) as a follow-up equity financing method. PIPE has the advantage of lower cost, faster completion, and fewer SEC filing requirements over traditional SEO. PIPE is especially popular among small- to medium-sized firms which suffer from less-than-solid operation performance and restricted access to other financing means. Anderson and Zhang (2011) investigated the use of PIPE financing by bio-pharmaceutical firms in conjunction with their external contracting activity. They found that firms with a higher volume of external contracts (as an indicator for better operating performance) obtain better terms in PIPE financing thus have lower cost of capital. Haggard and Zhang (2010) provide a guide to PIPE for potential issuers that may benefit from this financing method.

Besides trying to make it independently, young or small firms can turn to more established ones for help. Danzon, Nicholson, and Pereira (2005) show that alliances formed between young biotech and large pharmaceutical firms tend to increase the success rate of Phase 2 and Phase 3 clinical trials when a large firm is the licensee. Their results 
indicate that besides capital infusion as suggested by Lerner et al. (2003), small biotech firms also benefit from the alliance in terms of enhanced R\&D productivity. Nicholson, Danzon, and McCulloch (2005) show that biotech-pharmaceutical alliances also serve as an indicator for firm quality: Biotech firms that have previous alliance contracts with big pharmaceutical companies receive higher valuation from subsequent venture capital funding and public equity financing.

Certain legislations, namely the fast track program under the FDA Modernization Act of 1997, and the Orphan Drug Act, have also been shown to draw wide application by young bio-pharmaceutical firms. The next section provides information in this regard.

\section{FDA Fast Track Designation and the Orphan Drug Act}

The fast track program was initiated under the FDA Modernization Act of 1997 (FDAMA). To qualify for this program, a drug candidate must be aimed at addressing "unmet medical conditions"; that is, for diseases for which no effective treatments currently exist, or for which the proposed product could demonstrate substantial improvement over current methods. The benefits of being on the fast track include (frequent) meetings with the FDA on clinical trial designs, possible accelerated approval and priority review, and rolling NDA submission as clinical trial results become available rather than having to wait for all testing results to be in place for complete filing. In essence, the main benefit of being on the "fast track" is timely communication with the FDA that may lead to faster revelation of the fate of the drug candidate- either success or failure. Fast track designation does not provide any financial benefits to the drug sponsors, nor does it guarantee or increase the probability of drug approval.

Although no direct monetary benefit is associated with the fast track designation, it has been shown that the stock market reacts positively to such announcements, especially those of small firms. Anderson and Zhang (2010) studied 109 publicly announced fast track designations granted during 1998-2004. They found that 73 of the 109 sample firms were small bio-pharmaceutical firms that did not have any marketed products at the time of fast track designation. The announcements induced an average $9 \%$ abnormal return (robust under various benchmarks) and an increase in institutional ownership. The eventual outcome of "fast tracked" drug candidates, however, did not seem to meet investor expectations manifested through the stock price reaction. The approval rate of "fast tracked" drug candidates are no higher than that of drugs on the regular track, and there has never been any indication that such candidates should enjoy higher approval rates. Many remain "under development" years after the fast track designation. Mini-cases of the fast track designation are included in the appendix.

To encourage the research, development, and approval of products that treat rare diseases for which research and development otherwise might not be financially attractive for drug companies to pursue, the U.S. Congress passed the Orphan Drug Act on January 4, 1983. It is estimated that a total of 20 million Americans suffer from 5,000 rare diseases. To qualify for orphan drug status, the potential affected patients in the U.S. must be less than 200,000, and there must not be an existing treatment for the disease; or the drug candidate must show substantial improvement over the existing method. The Act provides the following benefits to orphan drug sponsors:

1. Tax credit for clinical development cost;

2. Seven years of market exclusivity once the orphan product is approved;

3. Possible orphan drug research grants and coordination and assistance from the FDA for research and clinical trial designs.

The objective of the Orphan Drug Act is to promote social welfare by providing certain incentives to sponsors. A rare disease can trigger multiple designations when multiple firms decide to work on it; however, only one firm is supposed to win the race and enjoy the seven-year market exclusivity. Even when an orphan drug is approved for marketing, given the small patient pool, the potential monetary profit is often limited. Shulman and Sheila (1997) provide an excellent review of the program since its inception till 1995.

The FDA maintains a searchable database on all designations and approvals under the Orphan Drug Act. (Note 9) The data shows a disproportionally high percentage engagement of young or small bio-pharmaceutical firms in the research and development of orphan drugs. Positive stock price reaction to orphan drug status as granted by the FDA has also been observed. However, similar to the fast track announcement, not much material advancement in terms of drug approval has been realized by the announcing bio-pharmaceutical firms.

In summary, both the FDA fast track program and the Orphan Drug Act have been widely used by young bio-pharmaceutical firms to promote investor recognition and gain short-term stock price appreciation. Nosolid evidence exists for long-term benefits for bio-pharmaceutical firms under these two programs, probably due to the nature of the long time period and the high capital investment requirements for successful drug development. 


\section{Surviving Market Volatility and Concluding Remarks}

The significant stock market decline in 2008 made equity financing very difficult to obtain. Young bio-pharmaceutical firms are among the hardest hit (Mitchell, 2008). Nevertheless, bio-pharmaceutical firms have proven to play an important role in the discovery and development of new drugs. The survival of these firms is vital for the well-being of the entire healthcare sector. Danzon, Epstein, and Nicholson (2007) studied the mergers and acquisitions in this industry. Their findings show that mergers among pharmaceutical companies tend to be in response to excess capacity due to pending patent expiration of blockbuster drugs, whereas deals among biotech firms serve as "exit strategy" in the presence of financial trouble and unsuccessful product development. The past decade has witnessed significant consolidation within the pharmaceutical industry - most recent megadeals include Pfizer's acquisition of Wyeth, and Merck's merger with Schering-Plough. The recent cash shortage at young bio-pharmaceutical firms presents investment opportunity for cash-rich big pharmaceutical firms to replenish their drug development pipeline at bargain prices.

The past five years have been quite a roller-coaster ride for the U.S. stock market. The broad-based S\&P 500 index dropped from its highest point of over 1500 in July 2007, to its lowest point of less than 700 in March 2009. Since then, it gradually recovered to the 1400 level as of March 2012 with unprecedented daily volatility. Since 2011, there have been signs that equity issuances, both IPO and SEO, are returning to the market. High profile IPOs include Zynga, LinkedIn, and Groupon. Other economic measures, such as GDP, new unemployment claims, and consumer price index all point to small yet steady recovery. Therefore, the outlook for equity financing for bio-pharmaceutical firms should improve as well.

The nature of scientific discovery in general, and bio-pharmaceutical research in particular, is challenging, lengthy, costly, and risky. As a major player in the global health economy, understanding the characteristics of the bio-pharmaceutical industry in the U.S.-including the regulatory environment, the industry and corporate structure, and the financing options — as this paper sketches out, helps firms expand into the U.S. market, optimize the growth and financing choices, and maximize the returns to investments.

\section{References}

Anderson, C. W., \& Zhang, Y. J. (2010). Market reaction to FDA fast track designation. Journal of Health Care Finance, 37(2), 26-47.

Anderson, C. W., \& Zhang, Y. J. (2011). Equity financing and external contracting: Evidence from the biopharmaceutical industry. Unpublished manuscript, School of Business, University of Kansas, Lawrence, KS.

Asensio, \& Company Inc. (1998). Hemispherx CFS phase III and orphan approvals found to be six years old [Press Release]. Retrieved from http://www.asensio.com/Data/Pdfs/245.pdf

Danzon, P. M., Epstein, A., \& Nicholson, S. (2007). Mergers and acquisitions in the pharmaceutical and biotech industries. Managerial and Decision Economics, 28, 307-328. http://dx.doi.org/10.1002/mde.1343

Danzon, P. M., Nicholson, S., \& Pereira, N. S. (2005). Productivity in pharmaceutical-biotechnology R\&D: The role of experience and alliances. Journal of Health Economics, 24(2), 317-339. http://dx.doi.org/10.1016/j.jhealeco.2004.09.006

Gapenski, L. C. (2012). Healthcare finance: An introduction to accounting and financial management (5th ed.). Arlington, Virginia: AUPHA/HAP.

Guedj, I., \& Scharfstein, D. S. (2005). Organizational scope and investment: Evidence from the drug development strategies and performance of biopharmaceutical firms. NBER Working Paper, No. w10933. Retrieved from the National Bureau of Economic Research website:http://ssrn.com/abstract=625564

Haggard, K. S., \& Zhang, Y. J. (2010). Traditional sources of capital dried up? A guide to private investment in public equity (PIPE) for new issuers. Journal of Financial and Economic Practice, 10(2), 12-27.

Lerner, J. (1994). Venture capitalists and the decision to go public. Journal of Financial Economics, 35(3), 293-316. http://dx.doi.org/10.1016/0304-405X(94)90035-3

Lerner, J., Shane, H., \& Tsai, A. (2003). Do equity financing cycles matter? Evidence from biotechnology alliances. Journal of Financial Economics, 67, 411-446. http://dx.doi.org/10.1016/S0304-405X(02)00256-8

Lipsky, M. S., \& Sharp, L. K. (2001). From idea to market: The drug approval process. Journal of the American Board of Family Practice, 14, 362-367. 
Mitchell, P. (2008). US credit crunch impacts biotech across the globe. Nature Biotechnology, 26(4), 359-360. http://dx.doi.org/10.1038/nbt0408-359

Nicholson, S., Danzon, P. M., \& McCulloch, J. (2005). Biotech-Pharmaceutical Alliances as a Signal of Asset and Firm Quality. Journal of Business, 78(4), 1433-1464. http://dx.doi.org/10.1086/430865

Ritter, J. (1998). Initial public offerings. Contemporary Finance Digest, 2(1), 5-30.

Shulman, S. R., \& Manocchia, M. (1997). The U.S.orphan drug program 1983-1995. Pharmacoeconomics, 12(3), 312-326. http://dx.doi.org/10.2165/00019053-199712030-00004

\section{Notes}

Note 1. Retrieved from http://www.oecd.org/document/30/0,3746,en_2649_33929_12968734_1_1_1_1,00.html

Note 2. Major industries in the healthcare sector include health services, health insurance, medical equipment and supplies, pharmaceuticals and biotechnology, other (p. 4).

Note 3. Retrieved fromhttp://csdd.tufts.edu/news/complete_story/pr_outlook_2011

Note 4. Genentech has been taken private since 2010.

Note 5. Retrieved fromhttp://www.fda.gov/Drugs/ResourcesForYou/Consumers/ucm143534.htm

Note 6. Retrieved fromhttp://www.fda.gov/NewsEvents/Newsroom/PressAnnouncements/2004/ucm108361.htm

Note 7. Retrieved fromhttp://www.fda.gov/NewsEvents/Newsroom/PressAnnouncements/ucm280536.htm

Note 8. Retrieved fromhttp://www.sec.gov/answers/regfd.htm

Note 9. The searchable database on all designations and approvals under the Orphan Drug Act is accessible at http://www.accessdata.fda.gov/scripts/opdlisting/oopd/index.cfm

Note 10. For example, in September 2002, VaxGen was selected by the National Institute of Allergy and Infectious Disease (NIAID), to develop a new anthrax vaccine for civilian use. This contract is up to $\$ 16.2$ million pending successful Phase 1 safety testing.

Note 11. The company changed its name to Biogen IDEC in 2003.

Note 12. Rituxan was co-developed by IDEC and Genentech.

\section{Appendix}

Mini-Cases of Stale News Release and FDA Fast Track Designations

\section{Case \#1: Stale News Release}

Most firms make timely news releases on clinical development of their drugs, while some try to "time the news release” for their advantage. The following news excerpt (Asensio \& Company Inc., 1998) illustrates one such case.

Asensio \& Co. (Asensio), a member of the National Association of Securities Dealers, announced that on October 9, 1992, the Food and Drug Administration (FDA) authorized HemispherxBiopharma Inc. (Hemispherx) to administer Ampligen CFS Phase III clinical trials. This means that Hemispherx could have conducted Ampligen's Phase III CFS trials during those six years. However, the company indicated to investors that the Phase III trials were a major new development. In this six-year period, Hemispherx failed to conclude the Phase III trial, allowing Hemispherx to promote its stock based on fraudulent misrepresentations of a flawed, seven-year-old Phase II trial (Asensio \& Company Inc., 1998, para. 1). Furthermore, in December 1993, the FDA designated Ampligen as an Orphan Drug. Asensio believes "that both the 1992 Phase III approval and the 1993 Orphan drug designation provide clear and convincing evidence that Hemispherx's representations concerning Ampligen's CFS sales potential and FDA approval status are entirely false and misleading” (Asensio \& Company Inc., 1998, para. 2).

\section{Case \#2: VaxGen Fast Track Designation}

VaxGen Inc. was founded in 1995 and operates in South San Francisco, California.It went public in June 1999 with a focus on the development of prevention and treatment of HIV/AIDS, anthrax, and other human infectious diseases. The AIDS vaccine (AIDSVAX) was undergoing two independent Phase 3 clinical trials as of December 2002.

VaxGen gets its revenue mainly from governmental research grants or through collaboration agreements with other bio-pharmaceutical firms. (Note 10) For fiscal year ending December 31, 2002, VaxGen had total revenue of $\$ 1.055$ million, R\&D cost of $\$ 20.975$ million, and net operating loss of $\$ 33.766$ million. Its book value of equity 
stood at \$14.495 million as of December 2002.Total revenue since VaxGen's inception (until end of 2002) was $\$ 2.752$ million, where total R\&D cost was $\$ 81.834$ million, and an accumulated loss of $\$ 142$ million. As of December 31, 2002, VaxGen had 117 employees, of whom 67 were R\&D and clinical staff, 17 were in manufacturing and regulatory and quality control, and 33 were management and administrative staff.

On December 16, 2002, VaxGen announced FDA fast track designation to its HIV/AIDS vaccine candidates, AIDSVAX B/B and AIDSVAX B/E, which were being evaluated in two separate Phase 3 clinical trials for AIDS prevention.

The stock market reacted positively on VaxGen's announcement of FDA fast track designation. Its stock closed at \$13.01 per share the day before the announcement with a total market capitalization of \$203.23 million, the stock price went up to $\$ 15.73$ at close on the day of announcement (a $20.91 \%$ one-day return), with continued run-up to $\$ 17.60$ at close the day after the announcement (11.89\% higher than announcement day).

With respect to trading volume, during the three-day event period, out of total 15,621 thousand shares outstanding, 2,304 thousand, 3,513 thousand, and 2,681 thousand shares changed hands on the days before, during, and after the announcement, respectively. The standardized abnormal trading volume was 13.6, 21.1, and 15.9, respectively. Institutional holding of VaxGen's stock increased significantly ending the quarter of the announcement, increasing from 26 institutions holding $8.36 \%$ of outstanding shares in the previous quarter, to 41 institutions holding $12.78 \%$ of all shares outstanding.

In 2003, VaxGen ceased almost all development efforts for AIDSVAX due to insignificant results from both Phase 3 clinical trials. In November 2004, VaxGen was awarded a contract for \$877.5 million to provide 75 million doses of anthrax vaccine by the U.S. government. However, this contract was "terminated for fault" due to VaxGen's inability to gain FDA approval for Phase 2 clinical trial initiation.

VaxGen's stock was delisted from the NASDAQ National Market in 2004. As of December 31, 2007, the company had 28 employees.

\section{Case \#3: IDEC Fast Track Designation}

IDEC Pharmaceuticals Inc. is a biopharmaceutical company that operates in San Diego, California. (Note 11) It was founded in 1985 and went public in September 1991. The company had annual operating losses since its inception until 1997 when its first product, Rituxan (for treatment of cancer in the immune system), was approved by the FDA and launched to the market. (Note 12) As of January 31, 2000, IDEC had 407 employees and approximately 114 independent contractors. For fiscal year ending December 1999, IDEC's total revenue was $\$ 118$ million, out of which \$43 million was spent on R\&D, which resulted in net income of \$43 million. IDEC's total book value of equity was roughly $\$ 160$ million by the end of 1999. Besides Rituxan, IDEC did not have other products on the market as of 2000. Its drug development pipeline consisted of ZEVALIN in Phase 3 clinical trials as a radio-immuno therapy for cancer, three drug candidates in Phase 2 clinical trials for treatment of autoimmune system and inflammatory diseases, plus another one in Phase 1 trial and a few others in pre-clinical testing.

On November 1, 2000, IDEC announced FDA fast track designation to ZEVALIN, a drug candidate for treatment of cancer of the lymphatic system. IDEC's market capitalization totaled at $\$ 8.92$ billion as of Oct. 31, 2000. Stock prices during the three-day event window closed at \$196.13, \$206.13, and \$218.06 per share, respectively. Daily raw returns were $6.16 \%, 5.10 \%$, and $5.79 \%$.

The three-day abnormal returns benchmarked to the biotech index were $0.35 \%, 1.09 \%$, and $-1.15 \%$, which led to a cumulative abnormal return of $0.29 \%$. Trading volume during the three-day event window was 1.17 million shares, 1.41 million shares, and 1.90 million shares, respectively, compared to the average volume of 1.02 million shares during the control period out of a total of 45.5 million shares. Standardized abnormal trading volume was 0.26 , 0.66 , and 1.48 , respectively. Turnover during the three-day event window was $2.58 \%, 3.11 \%$, and $4.19 \%$, compared to average turnover of $2.28 \%$ in the control period. The abnormal turnover was $0.22,0.62$, and 1.42 , respectively. Institutional ownership data showed 212, 256, and 233 institutions, reportedly holding 85\%, 96\%, and $88 \%$ of all outstanding shares at quarter's end around the announcement.

ZEVALIN was approved by the FDA for marketing in February 2002. It generated \$19.6 million in sales in 2003, its first full year on the market. The company changed its name to Biogen IDEC in 2003 and has grown substantially since then. It had total revenue of $\$ 5.04$ billion and a net income of $\$ 1.23$ billion for fiscal year 2011 . 